This is the author's final, peer-reviewed manuscript as accepted for publication. The publisher-formatted version may be available through the publisher's web site or your institution's library.

\title{
Consumer valuation of alternative meat origin labels
}

Glynn T. Tonsor, Ted. C. Schroeder, Jayson L. Lusk

\section{How to cite this manuscript}

If you make reference to this version of the manuscript, use the following information:

Tonsor, G. T., Schroeder, T. C., \& Lusk, J. L. (2013). Consumer valuation of alternative meat origin labels. Retrieved from http://krex.ksu.edu

\section{Published Version Information}

Citation: Tonsor, G. T., Schroeder, T. C., \& Lusk, J. L. (2013). Consumer valuation of alternative meat origin labels. Journal of Agricultural Economics, 64(3), 676-692.

\section{Copyright:}

(C) 2012 The Agricultural Economics Society. Published by Blackwell Publishing.

Digital Object Identifier (DOI): doi:10.1111/1477-9552.12010

Publisher's Link: http://onlinelibrary.wiley.com/doi/10.1111/1477-9552.12010/full

This item was retrieved from the K-State Research Exchange (K-REx), the institutional repository of Kansas State University. K-REx is available at http://krex.ksu.edu 


\title{
Consumer Valuation of Alternative Meat Origin Labels
}

\author{
Glynn T. Tonsor, Ted. C. Schroeder, and Jayson L. Lusk \\ Forthcoming: Journal of Agricultural Economics
}

\begin{abstract}
:
Results from a split-sample survey of the U.S. population reveal consumers prefer meat products carrying origin information to unlabeled alternatives. Consumers are largely unaware of origin labeling laws and are indifferent to an important aspect of the implementation of current mandatory country of origin information rules in the U.S. In particular, consumers value meat products labeled "Product of North America" approximately the same as "Product of United States." Despite the similarity of these two labels, they have vastly different implications in terms of trade and segregation costs. Our results suggest that a transition from one label to the other is equally satisfying for the consumer while being less costly for processors and more acceptable to trade partners.
\end{abstract}

Keywords: consumer demand, mandatory country of origin labeling, meat, policy awareness, split sample experiment, willingness to pay, WTO

JEL Classifications: Q18, Q13, Q17, D12

*Tonsor is Associate Professor and Schroeder is University Distinguished Professor in the Department of Agricultural Economics, Kansas State University. Lusk is Professor and Willard Sparks Endowed Chair in the Department of Agricultural Economics, Oklahoma State University. Contact: Glynn Tonsor, gtt@agecon.ksu.edu, (785)-532-1518. The views expressed here are those of the authors and may not be attributed to the U.S. Department of Agriculture which the authors acknowledge for providing partial funding support for this research (200904126). The authors also acknowledge the valuable assistance of Kayode Ajewole, Andrea Granger, Daja Menefee, and Iddrisu Yahaya in development of the consumer survey. 


\section{Introduction}

The United States mandatory country of origin labeling law (MCOOL) for fresh meat products has been laden with substantial controversy since its inception. Proponents argue that consumers demand origin information and have the right to know the provenance of meat products they purchase. Opponents contest the regulation claiming compliance increases costs for producers, processors, and retailers with insufficient offsetting benefits. Trading partners, led by Canada and Mexico, challenged MCOOL and presented their case to the World Trade Organization (WTO). Trading partners do not object to origin labeling, instead they argue that the way the rule is administered makes MCOOL an unjustified non-tariff trade barrier. The WTO agreed and the United States appealed the WTO ruling. Central to the debate is the specific label information consumers want relative to product origin.

The main purpose of this article is to determine U.S. consumer preferences for alternative origin labels on meat products. Although several previous studies have estimated consumer willingness to pay (WTP) for meat from one origin over another, to our knowledge, no previous study has investigated preferences for alternative versions of provenance labels. This is important because the specific product label has major implications relative to industry compliance requirements and associated costs, consumer benefits and valuation, trading partner and WTO acceptability of origin labeling, and ultimately for the benefit-cost impacts of the policy. Central to benefit-cost assessment is how the policy is implemented and what base of comparison is used. Our experimental design was, in part, motivated by the observation that a major fast food chain (Wendy's), though exempt from MCOOL requirements, voluntarily began to advertise their meat was a "Product of North America." This is important given the broader debate regarding whether there was market failure prior to MCOOL implementation and unclear 
rationale regarding exempt products. As such, our study is important for both products subject to, as well as, those exempt from MCOOL.

\section{Background and Past Literature}

The 2002 Farm Bill amended the Agricultural Marketing Act of 1946 to require retailers to notify customers of the country of origin of muscle cut and ground meats. Legislation delayed the implementation of MCOOL until September 30, 2008. On January 15, 2009 the United States Department of Agriculture, Agricultural Marketing Service published a final rule that became effective on March 16, 2009 (USDA AMS, 2009a). Commodities covered in this final rule include muscle cuts of beef, chicken, pork, and several other species (Link, 2009).

The political contention over MCOOL has a dynamic history. In addition to delayed implementation, before enactment complaints were filed with the WTO by U.S. trading partners (Gabbett, 2009a), and within the U.S. industry economic impacts of MCOOL were intensely debated (Informa Economics, 2010). After implementation, six senators called for revision of MCOOL labeling rules to address "loopholes" (Gabbett, 2009b). In November of 2011, the WTO ruled, supporting several aspects of the grievance filed. In response, in March of 2012, the U.S. elected to appeal this WTO ruling. In June of 2012 the WTO Appellate Body upheld components of its March ruling including the finding that MCOOL results in less favorable treatment of imported Canadian cattle and hogs than domestic counterparts (WTO, 2012).

Existing literature regarding preferences for country of origin information on meat products is diverse (see Alfnes (2004), Lusk et al. (2006), Tanner-Ehmke, Lusk, and Tyner (2008), Verlegh and Steenkamp (1999), and Yu and Gao (2010)). Much of the consumer preference research has illustrated that U.S. consumers are willing to pay a premium for U.S.- 
origin beef and pork products over products from other countries (e.g., Gao and Schroeder 2009; Link 2009; Loureiro and Umberger 2007; Mennecke et al. 2007; Miranda and Kónya 2006; Umberger et al. 2003; Ward, Bailey, and Jensen. 2005). While assessing willingness-to-pay for U.S. over foreign meat is relevant to the debate on MCOOL, existing literature misses subtle, but important, methodological issues; one being the exact nature of how origin information is conveyed. ${ }^{1}$

Recent literature regarding country of origin labeling highlights the prominent role that benchmark selection (characterization of the "no policy" situation or status quo) has in examining economic welfare impacts of mandatory policies (Awanda and Yiannaka, 2012; Joseph, Lavoie, and Caswell, 2009). In particular, using a comparison base of voluntary labeling leads to different conclusions regarding mandatory policy impact than using a no labeling base assumption. The fact that some exempt products are using voluntary origin labeling information indicates different base labels exist and need to be assessed in valuation of alternative origin labels.

In the context of this study we know specific labels which are compliant with MCOOL and we have available origin information characterizing the broader marketplace for meat products. The array of labels and other sources of origin information presented to consumers today is much richer than that mimicked by studies using only one treatment such as "Would you be willing to pay this premium to guarantee that your beef is Certified U.S. Beef?" (Loureiro and Umberger, 2003). Combining this with the importance of different comparison bases for welfare assessment, the observation of exempt and non-exempt industry segments being stakeholders, and the need for assessment across different meat products led to our use of a split sample design.

\footnotetext{
${ }^{1}$ To be fair to most existing studies, the majority were conducted prior to implementation of MCOOL.
} 


\section{Methods}

In April 2012, an online survey focused on labeling preferences for meat products was completed by 2,001 U.S. residents. Respondents were recruited from a large opt-in panel maintained by Survey Sampling International, which is designed to be representative of the U.S. population. To determine preferences for various origin labels on meat products from different species, a split-sample design was utilized in which different subjects were randomly assigned to different survey-treatments that varied according to: (i) the meat product being valued and (ii) the content of the origin label.

Subjects were asked a double bounded, dichotomous choice question (Hanemann, Loomis, and Kanninen, 1991): “Would you buy a 12 oz. boneless \{meat product\} labeled as $\{$ label $\}$ if it cost $\$ X$ MORE than a 12 oz. boneless $\{$ meat product $\}$ without a country of origin label? YES OR NO.” The split-sample design included meat product being either: beef steak, pork chop, or chicken breast and label being one of three different labels: Product of United States; Product of Canada, Mexico, and U.S.; or Product of North America. Specific information defining the label treatments (e.g., information on which countries are part of "North America" or the relevance of country ordering on a multi-country label) was not provided, which is consistent with the type of information that is currently being received by U.S. residents. As such, each label is clearly subject to interpretation by consumers as to what countries were or were not involved in production.

One-third of respondents were randomly allocated to each label treatment while $40 \%$, $40 \%$, and $20 \%$ were randomly allocated to the beef steak, pork chop, and chicken breast meat 
treatments, respectively. ${ }^{2}$ If the respondent answered YES to the initial choice question, they were subsequently asked if they would buy the labeled product if it $\operatorname{cost} \$(2 * X)$ MORE. Conversely, if the participant answered NO, they were subsequently asked if they would purchase the labeled product if it cost $\$\left(0.5^{*} X\right)$ MORE. The initial premium $(X)$ varied randomly across surveys ranging from $\$ 0.01$ to $\$ 4.00$.

Inclusion of three different meat products allows impacts across species to be explored. In each species, we focused on high-valued muscle cuts commonly studied in previous literature. ${ }^{3}$ Similarly, the three different labels studied were chosen to reflect industry debate during MCOOL implementation, the ongoing debate with the WTO, and efforts of industry segments exempt from MCOOL regarding the use of various labels and claims. The Product of United States label reflects what many advocates of MCOOL desire and is consistent with "Category A" consideration by USDA (USDA, 2009b). ${ }^{4}$ The Product of Canada, Mexico, and U.S. is a label some meat packers preferred to reduce implementation costs, and was the focus of debate when MCOOL was implemented. ${ }^{5}$ This label is consistent with "Category B" consideration by USDA (USDA, 2009b) and may apply in a situation where livestock were born and possibly raised elsewhere but slaughtered in the U.S.

The Product of North America label reflects what some meat packers have advocated to replace current rules, and is exemplified by the marketing of "Pure North American 100\% Fresh

\footnotetext{
${ }^{2}$ The smaller sample allocated to the chicken breast treatment reflects a larger focus on beef and pork demand issues assessed in segments of the surveys presented to participants after this contingent valuation assessment. That is, the segments of the surveys not presented here were more focused on beef and demand issues leading to the intentional collection of a smaller set of chicken breast treatment responses.

${ }^{3}$ Future research is encouraged to conduct parallel assessments on ground products and muscle cuts of less relative value to consumers to examine the ability to generalize findings across products for a given species.

${ }^{4}$ USDA has identified four meat labeling categories: A - U.S. Origin, B-Multiple Countries of Origin, C-Imported for Immediate Slaughter, and D-Foreign Origin (USDA, 2009b).

${ }^{5}$ Example media is: http://www.agweb.com/agday/blog/The_Independent_Cattleman_147/What_Is_the_Matter_with_M-COOL_17317/.
} 
Beef' by Wendy's ${ }^{\circledR}{ }^{6}$ This label captures information consumers may receive from restaurants who are exempt from MCOOL (USDA, 2009a). Including the Product of North America label in our study also captures aspects of the partial implementation and benchmark selection (no labeling vs. voluntary labeling) noted in the literature as important. Recalling that the base of each presented question is a no labeling situation, our survey-treatments allow key comparisons of interest to be made including: a) mandatory labels (Product of United States and Product of Canada, Mexico, and U.S.) against a base of no labeling; b) voluntary labels (Product of North America) against a base of no labeling; and c) mandatory labels (Product of United States and Product of Canada, Mexico, and U.S.) against voluntary labels (Product of North America). ${ }^{7}$

Combined, these comparisons contribute much more to our understanding of key MCOOL economic considerations. Our use of these three labels does not presume anything regarding acceptability by WTO in the current MCOOL debate nor acceptability by USDA. However, the labels were selected to cover a spectrum of the types of labels being promoted by various stakeholders in the U.S. meat industry as well as the types of origin information U.S. consumers currently face.

Given our split-sample design, varying meat products and labels enables a rich evaluation of consumer preferences, significantly expanding existing literature. Responses to the doublebounded dichotomous choice question can be used to infer an interval around each respondent's willingness to pay. Accordingly, to analyze the responses we estimated an interval-censored model following Cameron (1988) and Cameron and Quiggin (1994). We assume consumer i's true willingness to pay for meat product $j$ with origin label $k$ :

\footnotetext{
${ }^{6}$ See Wendy's "It's All About The Beef" video available at: http://www.wendys.com/food/Family.jsp?family=1. As of November 9, 2012 this was viewed 12,662 times on www.youtube.com.

${ }^{7}$ As noted by a reviewer, what exists as a mandatory or voluntary label could change in the future but this characterization of our three treatments reflects the situation faced by U.S. residents at the time of our study.
} 


\section{(1) $W T R_{t j k}^{\text {in }}=X_{t} \beta_{t k}+s_{t i k s}$}

where $X_{t}$ is a vector of explanatory variables pertaining to respondent $i, \beta_{i k}$ is a conformable vector of coefficients, and $\S_{t \downarrow k}$ is an idd normal error term with a standard deviation of ${\sigma_{t k}}^{8}$ If $P_{i, \text { low }}$ and $P_{i, h i g h}$ indicate the lowest and highest prices individual $i$ was willing to pay as indicated by their two discrete choices, we know that $P_{i, l o w} \leq W T P_{i j k}{ }^{*}<P_{i, h i g h .}$ Then the log-likelihood function for an interval censored regression can be written as:

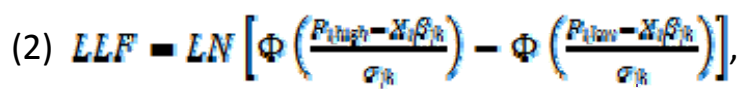

where $\Phi$ is the cumulative standard normal distribution function. If the model is estimated with only a constant term, then the constant is an estimate of the mean WTP (Cameron and Quiggin, 1994). To examine subject-specific characteristics and additional experimental-treatment impacts, additional explanatory variables of interest are added to the model and mean WTP can be identified using sample averages for the independent variables included. ${ }^{9}$

\section{Results}

Table 1 presents summary statistics for selected variables for the respondents allocated to the three different label treatments. As intended, the sample characteristics are consistent with the demographics of the U.S. population. We fail to reject equivalence of the means of socio-

\footnotetext{
${ }^{8}$ It is also possible to analyze the choices directly and estimate a random utility model, as common in similar dichotomous choice applications. However, the two approaches are observationally equivalent (see Cameron, 1988). Accordingly, we analyze the direct choices in WTP-space rather than utility-space as it makes the coefficients of more direct use given the purpose of our analyses.

${ }^{9}$ Technically this is expected WTP rather than mean WTP as more commonly referred to in the literature. However, the magnitude of this difference is likely minimal so we adopt common nomenclature.
} 
economic variables across both label and meat treatments. ${ }^{10}$ Accordingly, comparisons of WTP across label (or meat product) treatments are not a result of differences in survey-respondent sample demographics.

A noteworthy result in table 1 is limited awareness of MCOOL. Only $23 \%$ of respondent were aware of MCOOL, 12\% incorrectly believed MCOOL was not law, and nearly two-thirds of respondents "don't know" whether MCOOL is a law. The lack of awareness further stands out given the timing of this survey. In particular, the United States had until March 23, 2012 to respond to the November 2011 ruling regarding MCOOL by the WTO. The survey was conducted at the time when the U.S. was officially electing to appeal the ruling generating numerous news stories, which we expected would heighten public awareness of MCOOL. Despite this, the majority of respondents were either unsure or not aware of MCOOL. Implications of this lack of awareness are an important component of this study. Our finding of limited awareness is consistent with the finding of Lusk and Briggeman (2009) that origin is among the least important of food values for U.S. consumers and with the observed limited origin information appearing on retail meat products prior to MCOOL implementation.

To assess the impacts of presenting consumers with different meat provenance labels, we first examined whether responses from participants in the three different label treatments could be pooled - i.e., whether mean WTP differed across the three labels. We initially estimated interval censored models separately for each label treatment. Then, the data were pooled across the three label treatments and a restricted model was estimated. A likelihood ratio test was used to test the null hypothesis that WTP was the same in each label treatment. As shown in table 2, we reject the hypothesis of common parameters across the three label treatments implying at least one of the label treatments had a significantly different mean WTP. The mean WTP

\footnotetext{
${ }^{10}$ Unless otherwise stated, a significance level of 0.05 is used throughout.
} 
estimates from the three models suggests a preference ordering of Product of North America (\$1.88 per 12 ounces), Product of United States (\$1.77), and Product of Canada, Mexico, and U.S. (\$1.07). ${ }^{11}$ Each of these WTP estimates is significantly greater than $\$ 0$ at the 0.05 significance level. This ordinal ranking motivated a deeper assessment in the form of pair-wise pooling tests. As indicated in table 2, we reject the hypothesis of WTP values being the same between the Product of Canada, Mexico, and U.S. and the other two treatments, indicating that this label is the least preferred. However, we fail to reject the hypothesis of equivalence between the Product of North America and Product of United States labels.

The magnitude of these WTP values are similar to, or less than, those identified in previous studies. For instance, Loureiro and Umberger (2007) estimate U.S. consumer WTP of $\$ 2.57(\$ / 1 b)$ for origin information on beef steaks. Gao and Schroeder (2009) estimated premiums ranging from $\$ 2.33$ to $\$ 9.14$ ( $\$ / 12 \mathrm{oz}$.) across different teatments for beef steak labeled as "Certified U.S. Product." Our WTP (\$/12 oz) estimate for beef steak, when pooled across label treatments, was $\$ 1.67$ (WTP in the pork chop and chicken breast treatments was $\$ 1.53$, and $\$ 1.44$, respectively). ${ }^{12}$

The models summarized in table 2 include pooled responses from participants varying in MCOOL awareness. To examine how MCOOL knowledge influences WTP for the three different labels, additional models were estimated for the sample sub-sets aware, unaware, and unsure of MCOOL. As shown in table 3, we reject the hypothesis of equal preferences for participants varying in MCOOL awareness. In fact, the mean WTP across the three labels is approximately double for respondents aware of MCOOL (\$2.53) compared to those who are

\footnotetext{
${ }^{11}$ Throughout our analysis, presented WTP values are dollars per $12 \mathrm{oz}$. boneless product evaluated.

${ }^{12}$ Consistent with most previous studies, our study is likely prone to hypothetical bias (Lusk, 2003; Tonsor and Shupp, 2011). We however are less concerned with that in our application given our focus on marginal WTP differences across treatments where the impact of hypothetical bias should be reduced as any bias is likely to apply about equally to each treatment (Lusk and Schroeder, 2004).
} 
unaware or unsure. This higher WTP of respondents aware of MCOOL is consistent with probable self-selection of information. That is, residents more interested in origin are more likely to seek out corresponding information and place greater value on origin conveying labels consistent with our findings.

Table 3 presents results indicating the influence of awareness on stated WTP. Consistent with table 2, we fail to reject equivalence of the Product of North America and Product of United States labels among both aware and unaware groups. However, respondents indicating they do not know about the law reveal a significant preference for products carrying the Product of North America label over the Product of United States label.

Results presented in both tables 2 and 3 combine responses across the three meat products evaluated leaving the question of differential impacts across species unaddressed. However, even when WTP in the beef steak, pork chop, and chicken breast treatments were examined separately, we failed to reject the hypothesis of equivalence between the Product of North America and Product of United States labels. Moreover, segmented analyses by both meat treatment and MCOOL awareness maintain equivalence in mean WTP between the Product of North America and Product of United States labels. The only case where this hypothesis is marginally rejected $(0.057$ level $)$ is in the pork chop treatment where we find a preference for Product of North America (\$1.87) labels over Product of United States (\$1.43).

The models discussed so far have omitted socio-economic characteristics, given our previous finding that there were not significant differences in these variables across treatments. However, to determine how WTP for meat labels vary by demographics, additional models were estimated (table 4). ${ }^{13}$ Dummy variables for meat product and respondent region of residence are

\footnotetext{
${ }^{13}$ Note equivalence of "Model 1" in table 4 and the first model summarized in table 2. Similar details for models underlying other tables and noted in-text but not explicitly presented are available from the authors upon request.
} 
generally not significant. Utilizing likelihood-ratio tests, we fail to reject both the hypothesis of meat product impacts jointly being zero as well as region of residence impacts jointly being zero. Consistent with tables 2 and 3, label treatments vary in significance and respondents aware of MCOOL expressed substantially higher WTP (at least $\$ 1.00$ per 12-ounce product across models). Females $(\$ 0.60)$, households with more adults $(\$ 0.16$ per adult) and higher incomes (\$5.00 per additional $\$ 1,000$ of income), and respondents who more frequently consume the evaluated meat products (\$0.69) exhibited higher WTP. Respondents who have obtained college degrees provided lower WTP estimates $(-\$ 0.20)$. Overall, these socio-economic variable drivers are similar to the findings of Loureiro and Umberger (2003). However, the impact of household traits is dominated by MCOOL awareness and origin labels.

\section{Discussion, Implications, and Conclusions}

The purpose of this study was to examine U.S. consumer preferences for origin information labels on meat products. Consumers are willing to pay premiums for products carrying origin labels. Product of Canada, Mexico, and U.S. labels are the least preferred. However, preferences are similar for products carrying Product of North America or Product of United States labels. There is a noteworthy lack of awareness by consumers regarding mandatory country of origin labeling (MCOOL) in the U.S.

Existing market-level impact studies (Brester, Marsh, and Atwood, 2004; Chung, Zhang, and Peel, 2009; Lusk and Anderson, 2004) reflect a distinct ordering of assumed MCOOL implementation costs from beef being highest, to pork, to poultry where costs are assumed minimal or non-existent. These studies provide estimates of the aggregate beef and pork demand increases necessary for MCOOL implementation to offset costs. We conclude that origin 
information has similar value across these meat species. Coupling this with inferences from existing market-level impact assessments suggests the poultry industry has benefited from MCOOL at the expense of beef and pork industries.

Only 23\% of survey respondents were aware of MCOOL. The majority of respondents were either unsure or unaware of MCOOL. This raises doubt on assertions made by MCOOL advocates that "consumers want to know" or "consumers deserve to know." Ultimately, the diverse awareness across the population underlies another driver of heterogeneous economic impacts from MCOOL's implementation. Narrowly, few respondents were aware of MCOOL and this minority revealed significantly stronger preferences for labels conveying origin information suggesting any changes to MCOOL will have varied impacts on different segments of the population. This awareness heterogeneity is similar to the preference heterogeneity noted by Uzea, Hobbs, and Zhang (2011) reinforcing that heterogeneous economic welfare impacts would follow any changes to MCOOL.

Previous studies have found WTP premiums for origin information but most existing studies have examined valuations of only a sole origin label (vs. an unlabeled option). In comparing three different labels to a base case of no labeling information, we obtain a similar finding. However, as found in previous research (i.e., Barreiro-Hurle, Gracia, and De-Magistris, 2010), we find conclusions drawn vary depending on the labels evaluated by consumers. Our study also allows multiple comparisons to be made including: a) mandatory labels (Product of United States and Product of Canada, Mexico, and U.S.) against a base of no labeling; b) voluntary labels (Product of North America) against a base of no labeling; and c) mandatory labels (Product of United States and Product of Canada, Mexico, and U.S.) against voluntary labels (Product of North America). However, we note that the purpose of this study was not to 
examine how consumers value the mandatory/voluntary nature of labeling but rather to assess how consumers value products carrying labels compliant with mandatory labeling and labels voluntarily provided.

Finding U.S. consumers do not value meat products carrying Product of United States labels over those with Product of North America labels is important for several reasons.

Requests by the U.S. meat processing industry to utilize Product of North America labels and our finding no evidence of premiums for Product of United States labels also has notable economic welfare implications. If a Product of North America label is less expensive to implement in the context of MCOOL and consumers fail to place higher value on products carrying Product of United States labels, aggregate welfare would be enhanced by utilization of Product of North America labels.

This of course says nothing about acceptability of labels to producers or MCOOL compliance as viewed by USDA or by WTO. Future research should explore in more detail why consumers are indifferent to certain origin labels and what they believe different origin labels mean. Our findings also reveal why parties exempt to MCOOL such as Wendy's elect to use "pure North American beef" claims in promoting their sourcing patterns. Narrowly, even if the public values origin information on labels, the question of what type of label and what level of origin specificity is worthy of additional research. Similarly, the spillover impact of exempt parties on non-exempt parties in the broader context of MCOOL is an area ripe for additional investigation. As noted by Awanda and Yiannaka (2012), it is also important to properly specify the status-quo benchmark in assessing the costs and benefits of MCOOL.

Batte et al. (2007) found consumers presented a product with the National Organic Program seal were more likely to pay a premium but the seal did not increase the premium 
conditional on a consumer being willing to pay a premium: - the organic seal influenced the willingness of consumers to pay a premium but not the size of the premium This observation coupled with the growing literature regarding food product labels and quality cue effects (e.g. Gao and Schroeder, 2009; Tonsor, 2011) highlights an important possibility. Could origin labels convey broad quality information making respondents more willing to purchase products carrying origin labels (over unlabeled alternatives), yet not exhibit marginal impacts on the willingness to pay for differentials in specific origin sourcing varying across labeled products in origin information content? In our application, all three label treatments were valued significantly by respondents (where the base was an unlabeled situation), yet the marginal valuations in key treatments (Product of United States and Product of North America labels) were equal (where both offerings are labeled). This is consistent with the possibility of consumers desiring origin information as a product quality cue but being indifferent to the specifics of the information, as Lusk et al. (2006) suggest when noting that country of origin is associated with product quality. This is also consistent with Loureiro and Umberger (2007) that premiums for origin information are notably lower when respondents also receive food safety information.

Given the differences in costs associated with provision, the political contention within the U.S., and the ongoing WTO debate related to various labels and MCOOL the role of origin information warrants further research. 


\section{References}

Alfnes, Frode. 2004. "Stated Preferences for Imported and Hormone-Treated Beef: Application of a Mixed Logit Model." European Review of Agricultural Economics. 31:19-37.

Awada, L. and A. Yiannaka. 2012. "Consumer perceptions and the effects of country of origin labeling on purchasing decisions and welfare." Food Policy 37:21-30.

Barreiro-Hurle, J., Gracia, A. and De-Magistris, T. 2010. "The Effects of Multiple Health and Nutrition Labels on Consumer Food Choices." Journal of Agricultural Economics. 61:426-443.

Batte, M.T., N.H. Hooker, T.C. Haab, and J. Beaverson. 2007. "Putting their money where their mouths are: Consumer willingness to pay for multiingredient, processed organic food products." Food Policy 32:145-159.

Brester, G.W., J.M. Marsh, and J.A. Atwood. 2004. "Distributional Impacts of Country-OfOrigin Labeling in The US Meat Industry." Journal of Agricultural and Resource Economics 29(2):206-227.

Cameron, T.A. 1988. "A New Paradigm for Valuing Non-Market Goods Using Referendum Data: Maximum Likelihood Estimation by Censored Logistic Regression." Journal of Environmental Economics and Management 15(3):355-379.

Cameron, T.A., and J. Quiggin. 1994. "Estimation Using Contingent Valuation Data from a 'Dichotomous Choice with Follow-Up' Questionnaire.” Journal of Environmental Economics and Management 27:218-34.

Chung, C., T. Zhang, and D.S. Peel. 2009. "Effects of Country of Origin Labeling in the U.S. Meat Industry with Imperfectly Competitive Processors." Agricultural and Resource Economics Review 38:406-417.

Gabbett, J. 2009a. "Canada Relaunches COOL Complaint with WTO.” Meatingplace.com printed on April 28, 2009.

Gabbett, J. 2009b. "Senators ask Vilsack to re-open COOL." Meatingplace.com printed on February 6, 2009.

Gao, Z., and T.C. Schroeder. 2009. "Effects of Label Information on Consumer Willingness-toPay for Food Attributes." American Journal of Agricultural Economics 91(3):795-809.

Golan, E., F. Kuchler, L. Mitchell, C. Greene, and A. Jessup. 2000. "Economics of Food Labeling." U.S. Department of Agriculture, Economic Research Service, Agricultural Economic Report No. (AER793). 
Hanemann, W.M., J. Loomis, and B. Kanninen. 1991. "Statistical Efficiency of Double-Bounded Dichotomous Choice Contingent Valuation." American Journal of Agricultural Economics 73:1255-63.

Hanley, N., Adamowicz, W. and Wright, R. E. 2005. Price vector effects in choice experiments: an empirical test. Resource Energy Economics 27: 227-234.

Informa Economics Inc. 2010. "Update of Cost Assessments for Country of Origin Labeling Beef \& Pork." Available at: http://www.informaecon.com/COOLStudyUpdate2010.pdf.

Joseph, S., N. Lavoie, and J.A. Caswell. 2009. "Partial Implementation of COOL: Economic Effects in the U.S. Seafood Industry." Working Paper 2009-7. Department of Resource Economics, University of Massachusetts Amherst. Available at: http://people.umass.edu/resec/workingpapers/documents/ResEcWorkingPaper2009-7.pdf

Kuchler, F., B. Krissoff and D. Harvey. 2010. "Do Consumers Respond to Country-ofOrigin Labelling?” Journal of Consumer Policy 33:323-337.

Levitt, S. D. and List, J. A. 2009. Field experiments in economics: the past, the present, and the future. European Economic Review 53: 1-18.

Link, J.E. 2009. "Mandatory Country of Origin Labeling of Beef, Pork, Lamb, Chicken, Goat Meat, Wild and Farm-Raised Fish and Shellfish, Perishable Agricultural Commodities, Peanuts, Pecans, Ginseng, and Macadamia Nuts." The Federal Register / FIND 74(010):2658.

Louviere, J. J., Islam, T., Wasi, N., Street, D. and Burgess, L. (2008). Designing discrete choice experiments: do optimal designs come at a price? Journal of Consumer Research 35: $360-375$.

Loureiro, M.L. and W.J. Umberger. 2003. "Estimating Consumer Willingness to Pay for Country-of-Origin Labeling." Journal of Agricultural and Resource Economics 28(2):287-301.

Loureiro, M.L. and W.J. Umberger. 2007. “A Choice Experiment Model for Beef: What US Consumer Responses Tell us about Relative Preferences for Food Safety, Country-OfOrigin Labeling and Traceability." Food Policy 32(4):496-514.

Lusk, J. L. 2003. Effects of Cheap talk on Consumer Willingness-to-Pay for Golden Rice. American Journal of Agricultural Economics 85: 840-856.

Lusk, J.L., and J.D. Anderson. 2004. "Effects of Country-of-Origin Labeling on Meat Producers and Consumers." Journal of Agricultural and Resource Economics 29(2):185-205.

Lusk, J.L. and B.C. Briggeman. 2009. "Food Values.” American Journal of Agricultural Economics 91:184-196 
Lusk, J.L., J. Brown, T. Mark, I. Proseku, R. Thompson, and J. Welsh. 2006. “Consumer Behavior, Public Policy, and Country-of-Origin Labeling “ Review of Agricultural Economics 28:284-292.

Lusk, J. L. and Schroeder, T. C. 2004. "Are choice experiments incentive compatible? A test with quality differentiated beef steaks." American Journal of Agricultural Economics 86: 467-482.

Marta-Pedroso, C., H. Freitas, and T. Domingos. 2007. Testing for the Survey Mode Effect on Contingent Valuation Data Quality: A Case Study of Web Based versus In-Person Interviews. Ecological Economics 62: 388-398.

Mennecke, B.E., S.M. Lonergan, D.J. Hayes, and A.M. Townsend. 2007. "A Study of the Factors that Influence Consumer Attitudes toward Beef Products using the Conjoint Market Analysis Tool.” Journal of Animal Science 85(10):2639-2659.

Miranda, M.J., and L. Kónya. 2006. "Is Mandatory Country-of-Origin Labelling a Retrograde Step in the Long Run?" International Review of Retail, Distribution \& Consumer Research 16(5):579-590.

Rousu, M.C., W.E. Huffman, J.F. Shogren, and A. Tegene 2007. "Effects and Value of Verifiable Information in a Controversial Market: Evidence from Lab Auctions of Genetically Modified Food." Economic Inquiry 45:409-432.

Rude, J., J. Iqbal, and D. Brewin. 2006. "This Little Piggy Went to Market with a Passport: The Impacts of U.S. Country of Origin Labeling on the Canadian Pork Sector.” Canadian Journal of Agricultural Economics 54(3):401-420.

Tanner-Ehmke, M., J.L. Lusk, and W. Tyner. 2008. "Measuring the Relative Importance of Country-of-Origin in Consumer Food Preferences in China, France, Niger, and the United States." Agricultural Economics. 38:277-285.

Tonsor, G.T. 2011. "Consumer Inferences of Food Safety and Quality." European Review of Agricultural Economics. 38:213-235.

Tonsor, G.T. and R. Shupp. 2011. "Cheap Talk Scripts: Effectiveness in Online Choice Experiments and Private Good, Niche Market Assessments." American Journal of Agricultural Economics. 93:1015-1031.

Umberger, W., D. Feuz, C. Calkins, and B. Sitz. 2003. "Country-Of-Origin Labeling of Beef Products: US Consumers' Perceptions.” Journal of Food Distribution Research 34(03).

United States Department of Agriculture Agricultural Marketing Service (USDA AMS). 2009a. Federal Register, Vol. 74, No. 10.

United States Department of Agriculture Agricultural Marketing Service (USDA AMS). 2009b. Country of Origin Labeling website. Available at: http://www.ams.usda.gov/AMSv1.0/cool. 
Uzea, A. D., Hobbs, J. E. and Zhang, J. 2011. “Activists and Animal Welfare: Quality Verifications in the Canadian Pork Sector." Journal of Agricultural Economics, 62: 281304.

Verlegh, P.W.J., and J.-B.E.M. Steenkamp. 1999. "A Review and Meta-Analysis of Country-ofOrigin Research.” Journal of Economic Psychology 20(5):521-546.

Ward, R., D.V. Bailey, and R. Jensen. 2005. "An American BSE Crisis: Has it affected the Value of Traceability and Country-of-Origin Certifications for US and Canadian Beef?" International Food \& Agribusiness Management Review 8(2):92-114.

World Trade Organization (WTO). 2012. “Dispute Settlement: Dispute DS384.” Available at: http://www.wto.org/english/tratop_e/dispu_e/cases_e/ds384_e.htm

Yu, Xiaohua and Z. Gao. 2010. "Consumer Preferences for U.S. Beef Products: A Meta Analysis." Selected Paper prepared for presentation at the Agricultural \& Applied Economics Association 2010 AAEA,CAES, \& WAEA Joint Annual Meeting, Denver, Colorado, July 25-27, 2010. Available at: http://ageconsearch.umn.edu/bitstream/61033/2/YuGao-AAEA-11109-2010.pdf 


\begin{tabular}{|c|c|c|c|c|c|}
\hline Variable & Description & $\begin{array}{c}\text { Full } \\
\text { Sample } \\
(n=2,001)\end{array}$ & $\begin{array}{c}\text { Product of } \\
\text { United } \\
\text { States } \\
(n=667)\end{array}$ & $\begin{array}{l}\text { Product of } \\
\text { Canada, } \\
\text { Mexico, } \\
\text { and U.S. } \\
(\mathrm{n}=667)\end{array}$ & $\begin{array}{l}\text { Product of } \\
\text { North } \\
\text { America } \\
(n=667)\end{array}$ \\
\hline Female & 1 if female; 0 if male & 0.532 & 0.535 & 0.534 & 0.526 \\
\hline \multirow[t]{2}{*}{ Adults } & Number of adults in household & 2.109 & 2.099 & 2.111 & 2.118 \\
\hline & & $(0.971)$ & $(0.977)$ & $(0.941)$ & $(0.995)$ \\
\hline \multirow[t]{2}{*}{ Kids } & Number of children in household & 0.541 & 0.496 & 0.561 & 0.565 \\
\hline & & (0.996) & $(0.975)$ & $(0.954)$ & (1.057) \\
\hline \multirow[t]{2}{*}{ Age } & Age of respondent (years) & 47.120 & 47.270 & 47.145 & 46.945 \\
\hline & & $(16.411)$ & $(16.619)$ & $(16.157)$ & $(16.477)$ \\
\hline \multirow[t]{2}{*}{ Income } & Annual household income (000s) & 53.654 & 50.768 & 53.767 & 56.428 \\
\hline & & $(41.024)$ & (39.016) & $(41.141)$ & $(42.697)$ \\
\hline \multirow[t]{2}{*}{ College } & 1=Earned college degree; 0 & & & & \\
\hline & otherwise & 0.540 & 0.532 & 0.543 & 0.544 \\
\hline South & 1=South Region; 0 otherwise & 0.365 & 0.376 & 0.376 & 0.342 \\
\hline West & 1=West Region; 0 otherwise & 0.236 & 0.234 & 0.237 & 0.237 \\
\hline Midwest & 1=Midwest Region; 0 otherwise & 0.210 & 0.190 & 0.214 & 0.225 \\
\hline Northeast & 1=Northeast Region; 0 otherwise & 0.189 & 0.199 & 0.172 & 0.196 \\
\hline Travel - Canada & $\begin{array}{l}\text { 1=Has travelled to Canada; } 0 \\
\text { otherwise }\end{array}$ & 0.367 & 0.382 & 0.358 & 0.361 \\
\hline \multirow[t]{2}{*}{ Travel - Mexico } & 1=Has travelled to Mexico; 0 & & & & \\
\hline & otherwise & 0.336 & 0.322 & 0.351 & 0.334 \\
\hline \multirow[t]{3}{*}{ MCOOL Awareness $^{a}$} & 1=Aware ("Yes"); 0 otherwise & 0.233 & 0.229 & 0.219 & 0.252 \\
\hline & $\begin{array}{l}\text { 1=Unaware ("No"); } 0 \text { otherwise } \\
1=\text { Unsure ("I don't know"); } 0\end{array}$ & 0.122 & 0.135 & 0.132 & 0.100 \\
\hline & otherwise & 0.644 & 0.636 & 0.649 & 0.648 \\
\hline \multirow[t]{2}{*}{ Frequent Consumer $^{b}$} & $1=$ Consume product at least 2 times & & & & \\
\hline & per week; 0 otherwise & 0.136 & 0.148 & 0.109 & 0.151 \\
\hline Moderate & $1=$ Consume product $2-4$ times per & & & & \\
\hline Consumer ${ }^{b}$ & month; 0 otherwise & 0.498 & 0.501 & 0.502 & 0.490 \\
\hline
\end{tabular}

Notes: Presented values are variable means with standard deviations in parentheses. Consistent with the random allocation of labels, using t-tests we fail to reject (5\% level) equivalence of all presented non-consumption variables across label treatments. While not presented for brevity, we similarly fail to reject equivalence across the three meat treatments. South includes DE, MD, DC, VA, WV, NC, SC, GA, FL, KY, TN, MS, AL, OK, TX, AR, and LA; West includes ID, MT, WY, NV, UT, CO, AZ, NM, AK, WA, OR, CA, HA; Midwest includes WI, MI, IL, IN, OH, MO, ND, SD, NE, KS, MN, and IA; Northeast includes ME, NH, VT, MA, RI, CT, NY, PA, and NJ.

${ }^{a}$ Survey question was: "Are grocery stores currently required by law to label the country of origin for fresh [beef steak, pork chop, chicken breast] products? Yes, No, or I don't know."

${ }^{\mathrm{b}}$ Consumption was asked specific to beef steaks, pork chops, or chicken breasts depending on the meat treatment a participant was randomly allocated. 


\begin{tabular}{|c|c|c|c|c|}
\hline Sub-Sample Modeled & $n$ & $L L$ & WTP & $p$-value \\
\hline All respondents, all labels & 2,001 & -2628.347 & 1.566 & \\
\hline All respondents, Product of United States label & 667 & -878.485 & 1.772 & \\
\hline All respondents, Product of Canada, Mexico, and U.S. label & 667 & -849.180 & 1.073 & \\
\hline All respondents, Product of North America label & 667 & -886.091 & 1.882 & \\
\hline Ho: Pooling across three labels is okay & & & & 0.000 \\
\hline Ho: Pooling across Product of United States and Product of Canada, Mexico, and U.S. labels is okay & & & & 0.000 \\
\hline Ho: Pooling across Product of United States and Product of North America labels is okay & & & & 0.637 \\
\hline Ho: Pooling across Product of Canada, Mexico, and U.S. and Product of North America labels is okay & & & & 0.000 \\
\hline
\end{tabular}

Here $n, L L$, and WTP denote the number of respondents in each sub-sample, log-likelihood value of interval censored models, and point estimates of willingness to pay ( $\$ / 12 \mathrm{oz}$. boneless product), respectively. Models summarized here pooled across meat treatments, were specified to include intercept and scale parameters only, and were estimated with PROC LIFEREG in SAS. Presented p-values report results of log-likelihood ratio tests of whether respondents from different sub-samples of the examined population can be pooled. 


\begin{tabular}{|c|c|c|c|c|}
\hline Sub-Sample Modeled & $n$ & $L L$ & WTP & $p$-value \\
\hline All MCOOL aware respondents, all labels & 467 & -639.963 & 2.528 & \\
\hline All MCOOL unaware respondents, all labels & 245 & -300.881 & 1.225 & \\
\hline All MCOOL unsure respondents, all labels & 1,289 & -1649.391 & 1.357 & \\
\hline Ho: Pooling across MCOOL awareness is okay & & & & 0.000 \\
\hline All MCOOL aware respondents, Product of United States label & 153 & -202.111 & 3.221 & \\
\hline All MCOOL aware respondents, Product of Canada, Mexico, and U.S. label & 146 & -216.196 & 2.112 & \\
\hline All MCOOL aware respondents, Product of North America label & 168 & -217.470 & 2.306 & \\
\hline Ho: Pooling across three labels is okay & & & & 0.079 \\
\hline Ho: Pooling across Product of United States and Product of Canada, Mexico, and U.S. labels is okay & & & & 0.030 \\
\hline Ho: Pooling across Product of United States and Product of North America labels is okay & & & & 0.139 \\
\hline Ho: Pooling across Product of Canada, Mexico, and U.S. and Product of North America labels is okay & & & & 0.427 \\
\hline All MCOOL unaware respondents, Product of United States label & 90 & -112.216 & 1.646 & \\
\hline All MCOOL unaware respondents, Product of Canada, Mexico, and U.S. label & 88 & -90.414 & 0.651 & \\
\hline All MCOOL unaware respondents, Product of North America label & 67 & -87.031 & 1.811 & \\
\hline Ho: Pooling across three labels is okay & & & & 0.000 \\
\hline Ho: Pooling across Product of United States and Product of Canada, Mexico, and U.S. labels is okay & & & & 0.000 \\
\hline Ho: Pooling across Product of United States and Product of North America labels is okay & & & & 0.640 \\
\hline Ho: Pooling across Product of Canada, Mexico, and U.S. and Product of North America labels is okay & & & & 0.000 \\
\hline All MCOOL unsure respondents, Product of United States label & 424 & -537.450 & 1.406 & \\
\hline All MCOOL unsure respondents, Product of Canada, Mexico, and U.S. label & 433 & -523.702 & 0.918 & \\
\hline All MCOOL unsure respondents, Product of North America label & 432 & -575.955 & 1.760 & \\
\hline Ho: Pooling across three labels is okay & & & & 0.000 \\
\hline Ho: Pooling across Product of United States and Product of Canada, Mexico, and U.S. labels is okay & & & & 0.037 \\
\hline Ho: Pooling across Product of United States and Product of North America labels is okay & & & & 0.008 \\
\hline Ho: Pooling across Product of Canada, Mexico, and U.S. and Product of North America labels is okay & & & & 0.000 \\
\hline
\end{tabular}

Here $n, L L$, and WTP denote the number of respondents in each sub-sample, log-likelihood value of interval censored models, and point estimates of willingness to pay ( $\$ / 12 \mathrm{oz}$. boneless product), respectively. Models summarized here pooled across meat treatments, were specified to include intercept and scale parameters only, and were estimated with PROC LIFEREG in SAS. Presented p-values report results of log-likelihood ratio tests of whether respondents from different sub-samples of the examined population can be pooled. 
Table 4. Interval Censored Regression Estimates: Across Label Treatments

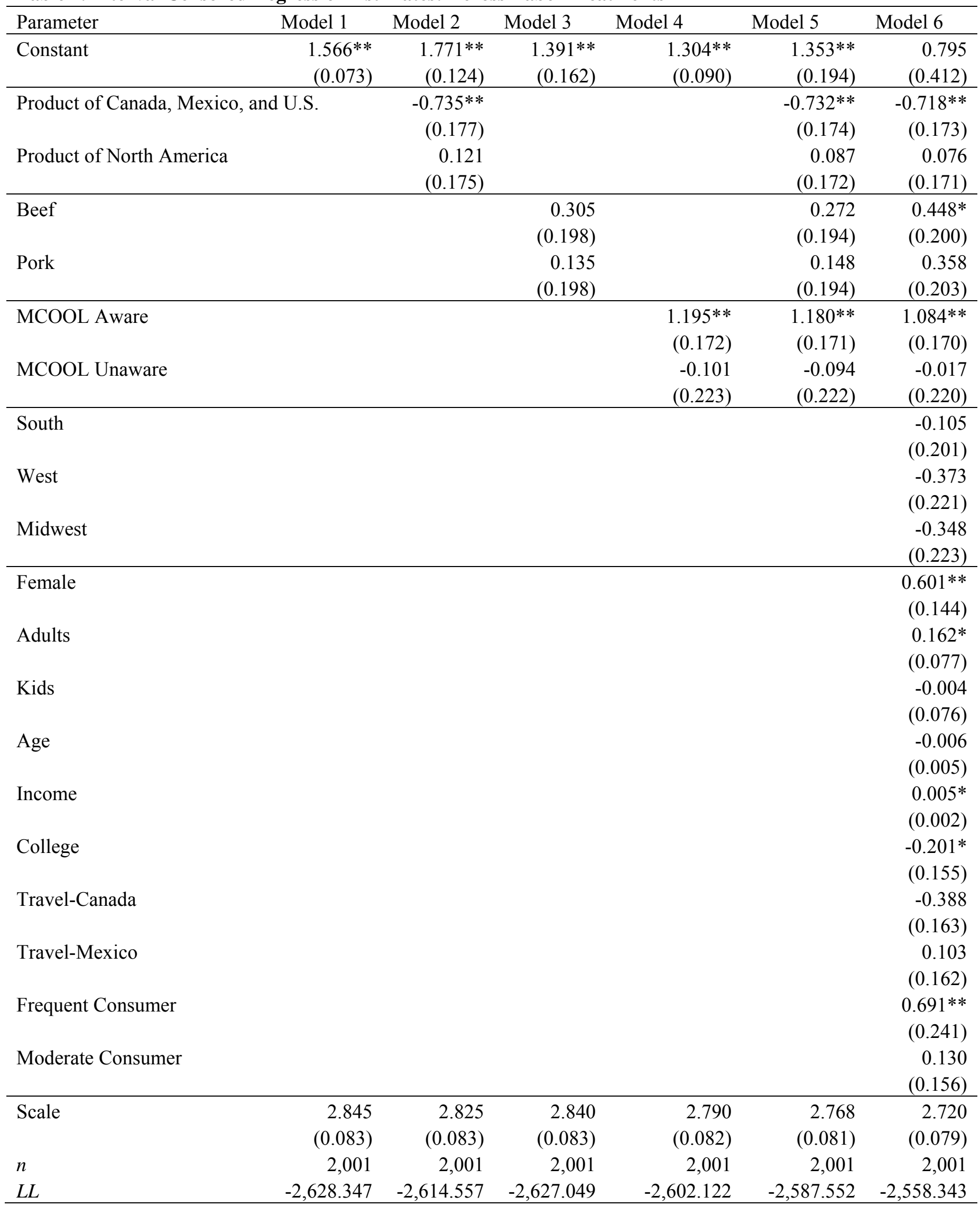

Numbers in parentheses are standard errors; ** and *denote $1 \%$ and 5\% significance level, respectively.

Parameters are defined consistent with previous tables. Models were estimated with PROC LIFEREG in SAS. 